\title{
PROSTHETIC LIMB USER EXPERIENCES WITH CROSSOVER FEET: A FOCUS GROUP STUDY TO EXPLORE OUTCOMES THAT MATTER
}

\author{
Cody L. McDonald*, Sarah M. Cheever, Sara J. Morgan, Brian J. Hafner
}

Department of Rehabilitation Medicine, University of Washington, Seattle, WA, USA.

* Email: codym@uw.edu

DOI: https://doi.org/10.33137/cpoj.v1i2.32042

\section{INTRODUCTION}

A variety of prosthetic feet are available to meet the diverse needs of people with lower limb amputation. Outcome measures selected to assess comparative effectiveness of prosthetic feet are most often chosen by clinicians and researchers. ${ }^{1}$ Therefore, these measures may not reflect the outcomes that are most important to lower limb prosthesis users. Qualitative research can give voice to prosthesis users and promote the consideration of user priorities when selecting outcome measures for clinical assessment and research studies. This study explored the lived experience and outcomes of importance to individuals who have worn both traditional energy storing feet and crossover feet.

\section{METHODS}

Sample: Convenience sample of prosthesis users Eligibility criteria: At least 18 years of age, lower limb amputation, at least 1 year prosthesis use, and prior use of an energy storing foot and crossover foot. Procedures: An in-person two-hour focus group was held. All procedures were approved by a UW IRB. Analysis: A phenomenological theoretical framework was applied to data analysis. Two investigators coded the focus group transcript independently, and a third mediated any discrepancies. Open coding was used to identify initial ideas. Axial coding and inductive reasoning were used to identify themes. Transcripts were reviewed to identify final themes and representative text. Investigators developed a framework of themes and identified instruments capable of measuring outcomes that mattered to focus group participants.

\section{RESULTS}

Five people with lower limb amputation (4 males/ 1 female), aged $41-59$ years (mean $45.6 \pm 7.7$ years), and who used a prosthesis daily (mean 15.2 \pm 1.1 hours) participated in the focus group. Three categories of themes arose from this focus group: direct outcomes, external influences, and indirect outcomes (Table 1).
Themes such as balance \& stability well matched standardized measures. Themes like naturalness and peer influence did not align with available measures, suggesting that new outcome measures may need to be developed. Other themes like endurance and sustained gait quality included elements (e.g., time of day, fatigue and gait symmetry) that may be challenging to capture with current assessment methods.

Table 1. Theme definitions

\begin{tabular}{|c|c|}
\hline Theme & Definition \\
\hline \multicolumn{2}{|c|}{ Direct outcomes } \\
\hline $\begin{array}{l}\text { Balance \& } \\
\text { stability }\end{array}$ & $\begin{array}{l}\text { Ability to maintain an upright, controlled } \\
\text { posture while standing and walking }\end{array}$ \\
\hline $\begin{array}{l}\text { Endurance \& } \\
\text { sustained } \\
\text { gait quality }\end{array}$ & $\begin{array}{l}\text { Ability to maintain activity over a prolonged } \\
\text { period of time without excessive fatigue or } \\
\text { degradation of walking performance }\end{array}$ \\
\hline Naturalness & $\begin{array}{l}\text { Perceptions of anatomical motion and sensory } \\
\text { feedback }\end{array}$ \\
\hline \multicolumn{2}{|c|}{ External Influences } \\
\hline $\begin{array}{l}\text { Peer } \\
\text { influence }\end{array}$ & $\begin{array}{l}\text { Relationships with other people with lower limb } \\
\text { amputation that affect outcomes }\end{array}$ \\
\hline $\begin{array}{l}\text { Prosthetist } \\
\text { influence }\end{array}$ & $\begin{array}{l}\text { Relationship with one's clinician that affects } \\
\text { outcomes }\end{array}$ \\
\hline
\end{tabular}

Indirect outcomes

Increased Enhanced trust in one's prosthesis and one's confidence own ability to try new activities

Expanded An increase in the diversity and type of mobility activities in which one engages

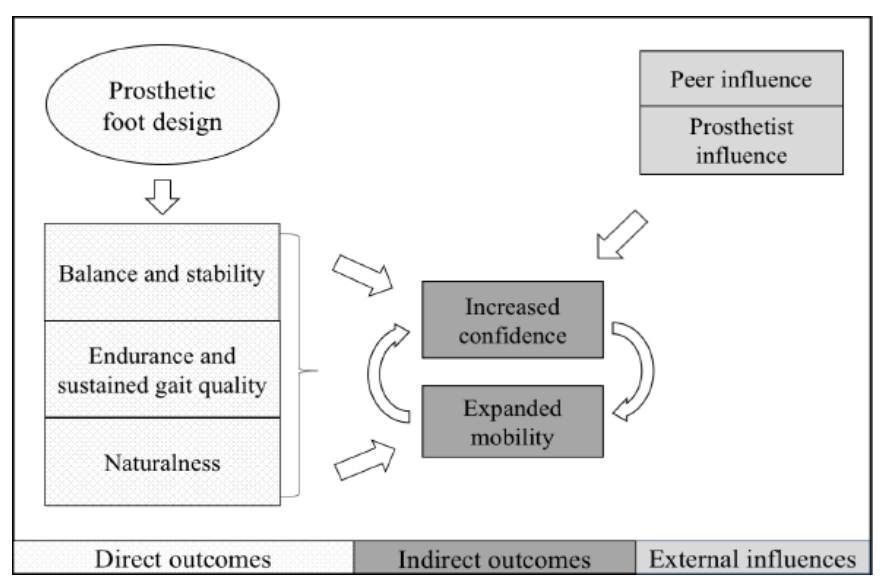

Figure 1. Framework of study themes 


\section{CONCLUSION}

Prosthesis user engagement through qualitative research can inform selection of outcomes that matter to users. Measurement of outcomes that matter may maximize clinicians' and researchers' ability to assess the effects of prosthetic interventions on users' lives.

\section{REFERENCES}

1.Hafner BJ. Energy storage and return prostheses: does patient perception correlate with biomechanical analysis? Clin Biomech. 2002; 17(5), 325-44. DOI: https://doi.org/10.1016/S0268-0033(02)00020-7

\section{DISCLOSURE}

This work was funded by a Walter C. and Anita C. Stolov Award and an Orthotics and Prosthetics Outcomes Research Award (No. W81XWH-15-1-0458). 